\title{
Size-based Separation of Supercoiled Plasmid DNA using Ultrafiltration
}

\author{
Ying Li, Neil Butler, Andrew L. Zydney \\ Department of Chemical Engineering \\ The Pennsylvania State University \\ University Park, PA 16802
}

Submitted to

J Colloid and Interface Sci

Communication concerning this manuscript should be addressed to:

Andrew Zydney, Department of Chemical Engineering,

The Pennsylvania State University, University Park, PA 16802

Phone: 814-863-7113, Fax: 814-865-7846

E-mail: zydney@engr.psu.edu 


\begin{abstract}
Hypothesis

Most previous studies of membrane-based separations have shown no effect of DNA size on plasmid transmission through small pore size ultrafiltration membranes, consistent with the predicted behavior for flexible polymer chains. However, supercoiled plasmids are known to have a highly "branched" structure with the number of branches dependent on the DNA length. This difference in branching could lead to a significant dependence of the transmission on the plasmid size, providing opportunities for size-based separations using ultrafiltration.

\section{Experiments}

Data were obtained with 3.0, 9.8, and $16.8 \mathrm{kbp}$ plasmids using both cellulosic and polyethersulfone ultrafiltration membranes with different nominal molecular weight cutoffs. Initial experiments were performed with purified samples of the supercoiled and linear isoforms, with the results used to identify appropriate conditions for plasmid separation.
\end{abstract}

\title{
Findings
}

Plasmid transmission increased with increasing filtrate flux due to elongation of the plasmids in the converging flow field. However, the flux dependence was different for each plasmid due to differences in the extent of branching of the twisted supercoiled DNA. This behavior provided a significant selectivity that could be used to separate the 3.0 and $16.8 \mathrm{kbp}$ supercoiled plasmids using small pore size ultrafiltration membranes.

Keywords: Ultrafiltration, DNA, supercoiled, plasmid, membrane separation 


\section{Introduction}

DNA purification is a critical step in many microbiological processes, forensic analyses, and in the large scale production of gene therapy agents and DNA based vaccines [1]. This includes the removal of other nucleic acids such as genomic DNA, RNA, and DNA dimers (e.g., linked plasmids), as well as plasmids with incorrect constructs [2]. These nucleic acid separations are particularly difficult since the DNA has similar surface charge and affinity, although there can be large differences in the size of these species.

Agarose gel electrophoresis (AGE) is the standard method for size-based DNA separation, with the DNA mobility through the gel arising from hydrodynamic interactions with the agarose matrix $[3,4]$. However, AGE is limited to laboratory-scale separations, it is very time-consuming, and it can be difficult to recover the DNA from the gel and remove the stain used for visualization. Density gradient centrifugation using $\mathrm{CsCl}$ can also be used for DNA separations, although this usually requires more than $16 \mathrm{~h}$ of ultracentrifugation [5].

Several size exclusion chromatography (SEC) resins have been specifically developed for DNA separations, including the Sephacryl S-1000 and the Superose 6B [6]. These large pore size resins can provide reasonable resolution for DNA separations, particularly between very large genomic DNA and smaller plasmids, although the throughput tends to be very low due to the significant diffusional resistance arising from the large size of the DNA [7]. In addition, baseline resolution can be difficult to achieve due to the broad peaks and the physical and chemical similarity between the impurities and supercoiled plasmid [8]. For example, McClung and Gonzales [9] used the Superose 6 resin for purification of plasmids from $E$ Coli extract containing DNA fragments with good resolution, but all plasmids from 4 to $150 \mathrm{kbp}$ eluted at the same retention volume, with no fractionation of these plasmids on the basis of size or length. 
Raymond et al. [10] used the Sephacryl S-1000 resin for purification of supercoiled DNA, with good (but incomplete) removal of RNA and genomic DNA for both 4.4 and $12 \mathrm{kbp}$ plasmids.

Membrane separations have replaced SEC in many size-based separations due to the large increase in throughput and the significant reduction in processing time. For example, buffer exchange in the formulation of therapeutic proteins is now done almost entirely by ultrafiltration / diafiltration [11,12]. Membrane systems can also be used for much higher resolution size-based separations, e.g., between protein monomers and dimers [13]. However, previous studies of membrane systems for DNA separations have generally shown little if any dependence of plasmid retention on the DNA size [14,15]. Latulippe and Zydney [14] hypothesized that this was due to the elongation of the plasmid in the converging flow field approaching the membrane pores, with the larger plasmids having more time to elongate as they approach the pore. This behavior is in good agreement with predictions of scaling models developed to describe the elongation of single polymer chains during passage through isolated small pores [16]. However, it is well known that supercoiled plasmids adopt a more complex 3-dimensional morphology, which could lead to very different behavior during ultrafiltration.

The objective of this study was to investigate whether ultrafiltration could be used for the separation of supercoiled plasmids based on differences in their size, i.e., number of base pairs. Initial experiments were conducted with purified plasmids of different size to determine the effect of the plasmid size on transmission through different pore size ultrafiltration membranes. Corresponding experiments were performed with linear plasmids to confirm the role of the supercoiled structure on the ultrafiltration behavior. Appropriate conditions were identified and then applied for the separation of a binary mixture of supercoiled plasmids with different size. The results were in good agreement with a simple physical model for the transmission of 
"branched" polymers, providing further confirmation of the potential for using ultrafiltration for size-based separation of supercoiled plasmid DNA.

\section{Materials and methods}

\subsection{Materials}

$200 \times 10^{-6} \mathrm{~kg} / \mathrm{m}^{3}(200 \mu \mathrm{g} / \mathrm{mL})$ stock solutions of supercoiled plasmids were obtained from Aldevron (Fargo, ND) and stored frozen at $-20{ }^{\circ} \mathrm{C}$. Three different size plasmids: 3.0, 9.8, and 16.8 kilo base pair (kbp), were used in the experiments. The linear plasmid isoforms were prepared from the supercoiled isoform using restriction endonucleases that recognize and cleave a specific nucleotide sequence in the double-stranded DNA. The $3.0 \mathrm{kbp}$ linear isoform was prepared using BamHI (New England Biolabs, MA). The digestion solution was made by mixing $25 \mu \mathrm{g}$ of supercoiled isoform with $1 \times \mathrm{CutSmart}^{\circledR}$ buffer and $50 \mathrm{U}$ of enzyme (2 U/ $\mu \mathrm{g}$ DNA). After incubation at $37{ }^{\circ} \mathrm{C}$ for 3 hours, the residual impurities (unwanted enzymes, salts, and DNA debris) were removed using a commercially available kit (QIAQuick PCR purification kit (Qiagen, CA)). A similar procedure was used to prepare linear isoforms of the other plasmids using KpnI for the $9.8 \mathrm{kbp}$ supercoiled plasmid and PaeR7I for the $16.8 \mathrm{kbp}$ plasmid.

Buffer solutions were prepared by diluting a 100× concentrate of $1.0 \mathrm{M}$ Tris-hydrochloride (Tris-HCl) and $0.1 \mathrm{M}$ ethylene-diaminetetraacetic acid disodium salt (EDTA- $\mathrm{Na}_{2}$ ) from SigmaAldrich. Deionized distilled water with a resistivity greater than $18 \mathrm{M} \Omega-\mathrm{cm}$ was produced using a NANOpure Diamond water purification system (Barnstead International, IL). The solution ionic strength was adjusted with sodium chloride $(\mathrm{NaCl})$. Buffers with $\mathrm{NaCl}$ concentrations of 10 , 150,300 , and $500 \mathrm{mM}$ were used, and the conductivity was measured by a Thermo Orion 105APlus conductivity meter. 
$25 \mathrm{~mm}$ diameter polyethersulfone $\left(\right.$ Biomax $\left.^{\circledR}\right)$ ultrafiltration membranes with nominal molecular weight cut-offs of $50 \mathrm{kDa}$ (PBQK02510), $100 \mathrm{kDa}$ (PBHK02510), and $300 \mathrm{kDa}$ (PBMK02510) were provided by MilliporeSigma. Limited experiments were also performed using $100 \mathrm{kDa}$ Ultracel $^{\circledR}$ composited regenerated cellulose membranes (PLHK02510, MilliporeSigma). Ultrafiltration membranes disks were soaked in $90 \%$ isopropyl alcohol prior to use. At least $2 \mathrm{~L} / \mathrm{m}^{2}$ of DI water was then flushed through the membrane to thoroughly wet the membrane pores.

\subsection{Assays}

DNA concentrations were evaluated by fluorescent detection using the ultrasensitive nucleic acid stain PicoGreen (Life Technology, CA). All DNA samples were analyzed in duplicate using Cliniplate 96-well black microplates (Thermo Scientific, PA) and a GENios FL microplate reader (TECAN). $70 \mu \mathrm{L}$ of the PicoGreen solution was prepared by diluting the stock reagent with TE buffer (1:200), with the reagent added to each well along with $70 \mu \mathrm{L}$ of the DNA sample. The plates were shaken for $3 \mathrm{~min}$, and the fluorescence intensity was evaluated at $530 \mathrm{~nm}$ using an excitation wavelength of $485 \mathrm{~nm}$ at a temperature of $36^{\circ} \mathrm{C}$. Calibration curves were constructed using DNA solutions with known concentrations from 0 to $0.5 \mu \mathrm{g} / \mathrm{mL}$, with accuracy of $0.25 \mathrm{ng} / \mathrm{mL}$. Since the Picogreen ${ }^{\circledR}$ fluorescence is weakly sensitive to the salt concentration [17], calibration standards were included in each plate at the different ionic conditions.

Agarose gel electrophoresis (AGE) was used to confirm the integrity and topology of the different plasmid isoforms. A $0.8 \%$ agarose gel solution was prepared by dissolving $0.36 \mathrm{~g}$ agarose powder and $4.5 \mu \mathrm{L}$ of GelStar ${ }^{\mathrm{TM}}$ nucleic acid gel stain (Lonza, NJ) in $45 \mathrm{ml}$ of TrisAcetate-EDTA (TAE) buffer. The agarose solution was poured onto a $7 \times 7 \mathrm{~cm}^{2}$ casting tray 
(Bio-Rad, CA) with an 8-well comb inserted, and allowed to set for 30 min at room temperature. The gel was then loaded into a Mini-Sub Cell GT (Bio-Rad) that had been pre-filled with about $200 \mathrm{~mL}$ TAE buffer, and the electrophoresis was conducted at a constant electric field of 45-55 V for 90-120 min. Gel images were obtained using a Fluorchem FC image system.

\subsection{Plasmid ultrafiltration}

A $10 \mathrm{~mL}$ stirred cell (MilliporeSigma) was used in the ultrafiltration experiments. The stirring speed was adjusted to $730 \mathrm{rpm}$ for all experiments. The pressure in the system was controlled by air pressurization of the polycarbonate feed reservoir that was connected to the stirred cell using pressures from 0 to $60 \mathrm{kPa}$ (approximately $0-8 \mathrm{psi}$ ). The filtrate flux was calculated as the volumetric filtrate flow rate divided by the membrane area $\left(4.1 \mathrm{~cm}^{2}\right)$, where the volumetric flow rate was determined by timed (mass) collection of the filtrate using a digital balance (Mettler Toledo). Two filtrate samples were taken after first collecting at least $1 \mathrm{~mL}$ of filtrate, which is approximately the hold-up volume beneath the membrane. Additional details on the plasmid ultrafiltration experiments are provided elsewhere [18]. The sieving coefficient was calculated as the ratio of the plasmid concentration in the filtrate and the corresponding feed samples. 


\section{Results and Discussion}

\subsection{Supercoiled plasmids}

Figure 1 shows the transmission of $0.20-0.25 \mu \mathrm{g} / \mathrm{mL}$ solutions of the individual 3.0, 9.8, and $16.8 \mathrm{kbp}$ supercoiled plasmids through a Biomax ${ }^{\circledR} 100 \mathrm{kDa}$ membrane as a function of filtrate flux. Two samples were obtained at each filtrate flux, with the concentrations measured in duplicate and reported as the mean values. The data were highly reproducible; the error bars on the sieving coefficients lie within the size of the symbols and are not shown. There was no evidence of membrane fouling during the experiments with these dilute plasmid solutions - the membrane hydraulic permeabilities before and after each ultrafiltration experiment were statistically indistinguishable. The integrity of the plasmids in both the feed and filtrate samples was confirmed by AGE; there were no visible structural changes of any DNA sample due to either filtration through the membrane or prolonged stirring during the ultrafiltration.

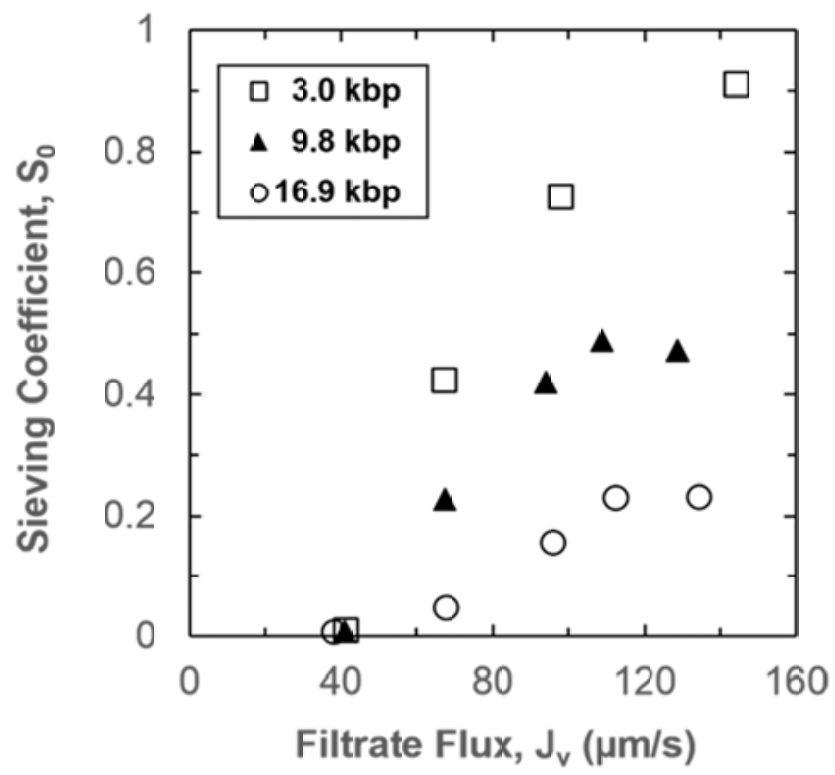

Fig. 1. Observed sieving coefficients of the 3.0, 9.8, and $16.8 \mathrm{kbp}$ supercoiled plasmids through the $100 \mathrm{kDa}$ Biomax ${ }^{\circledR}$ membrane in TE buffer with $300 \mathrm{mM} \mathrm{NaCl}$. 
The sieving coefficients for all three plasmids were essentially zero $\left(\mathrm{S}_{\mathrm{o}}<0.02\right)$ at filtrate flux below $40 \mu \mathrm{m} / \mathrm{s}$ (corresponding to $140 \mathrm{~L} / \mathrm{m}^{2} / \mathrm{h}$ ). The sieving coefficients increased significantly with increasing filtrate flux due to the elongation of the plasmid in the converging flow field entering the membrane pores as discussed previously [15]. Note that the $16.8 \mathrm{kbp}$ plasmid has a radius of gyration of $169 \mathrm{~nm}$ (determined by static light scattering [19]), while the mean pore radius of the Biomax ${ }^{\circledR} 100 \mathrm{kDa}$ membrane is less than $10 \mathrm{~nm}$. The largest sieving coefficients were obtained with the $3.0 \mathrm{kbp}$ plasmid. For example, at a filtrate flux around 140 $\mu \mathrm{m} / \mathrm{s}\left(500 \mathrm{~L} / \mathrm{m}^{2} / \mathrm{h}\right)$, the sieving coefficient of the $3.0 \mathrm{kbp}$ plasmid was above 0.9 while that for the $16.8 \mathrm{kbp}$ plasmid was below 0.25 . Similar behavior was observed at both lower and higher salt concentrations $(150$ and $500 \mathrm{mM})$, although the actual values of the sieving coefficient tended to increase slightly with increasing ionic strength.

As discussed by van Reis and Saksena [20], the critical parameter defining the separation performance of a membrane process is the selectivity, given by the ratio of the sieving coefficient of the more permeable species to that of the less permeable component:

$$
\psi=\frac{S_{1}}{S_{2}}
$$

where in this case the subscripts " 1 " and "2" would refer to the 3.0 and $16.8 \mathrm{kbp}$ plasmids, respectively. The data in Figure 1 have been re-plotted in Figure 2 in terms of the selectivity, evaluated using Equation (1) with the sieving coefficients for the 3.0 and $16.8 \mathrm{kbp}$ plasmids determined by interpolation of the raw data using a smoothed polynomial fit. The error bars were determined by standard propagation of error analysis. The large error bars at the small values of the filtrate flux are due to the small values of the sieving coefficients (and thus the large relative errors) under these conditions. The selectivity goes through a maximum value of approximately $\psi=9$ at a filtrate flux around $70 \mu \mathrm{m} / \mathrm{s}$ due to the more rapid initial increase in transmission of the 
$3.0 \mathrm{kbp}$ plasmid compared to that of the $16.8 \mathrm{kbp}$ plasmid at low filtrate flux. The reduction in selectivity at high flux is due to the increase in transmission of the larger plasmid.

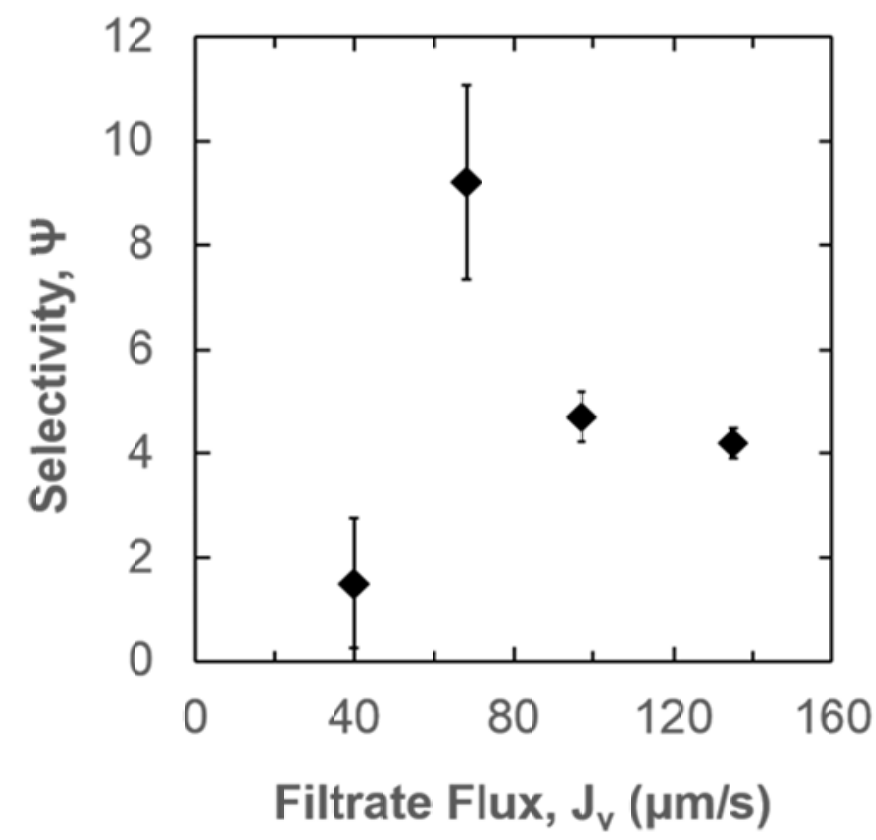

Fig. 2. Selectivity between the 3.0 and $16.8 \mathrm{kbp}$ supercoiled plasmids as a function of filtrate flux. Ultrafiltration experiments were performed using $100 \mathrm{kDa}$ Biomax ${ }^{\circledR}$ membranes in TE buffer containing $300 \mathrm{mM} \mathrm{NaCl}$. Error bars were determined by standard propagation of error analysis.

The effect of membrane pore size on the selectivity between the 3.0 and $16.8 \mathrm{kbp}$ plasmids is examined in Figure 3 based on data obtained with the Biomax ${ }^{\circledR} 50$ and $300 \mathrm{kDa}$ membranes in TE buffer containing $300 \mathrm{mM} \mathrm{NaCl}$. In each case, the maximum value of the selectivity is shown; this occurred at a filtrate flux of $110 \mu \mathrm{m} / \mathrm{s}$ for the $50 \mathrm{kDa}$ membrane and at $J_{\mathrm{v}}=5 \mu \mathrm{m} / \mathrm{s}$ for the $300 \mathrm{kDa}$ membrane. The selectivity was very low with the large pore size Biomax ${ }^{\circledR} 300 \mathrm{kDa}$ membrane, with $\psi<2.5$ for all conditions due to the similar (and relatively large) values of the sieving coefficients for both plasmids. The maximum selectivity for the Biomax ${ }^{\circledR} 50 \mathrm{kDa}$ membrane was only about $\psi \approx 4.5$ due to the high degree of retention for both plasmids through this small pore size membrane, with the greatest selectivity seen with the $\operatorname{Biomax}{ }^{\circledR} 100 \mathrm{kDa}$ 
membrane (data from Figure 2). It is possible that higher selectivities could have been achieved using the Biomax ${ }^{\circledR} 50 \mathrm{kDa}$ membrane, but this would have required very high filtrate flux (i.e., high transmembrane pressures) to obtain significant plasmid transmission through this small pore size membrane. The optimal pore size for a given plasmid separation is likely to depend on the size of the plasmid; membranes with very large pores will show minimal selectivity due to the high degree of transmission of both small and large plasmids while membranes with very small pores will show poor selectivity due to the very high degree of retention.

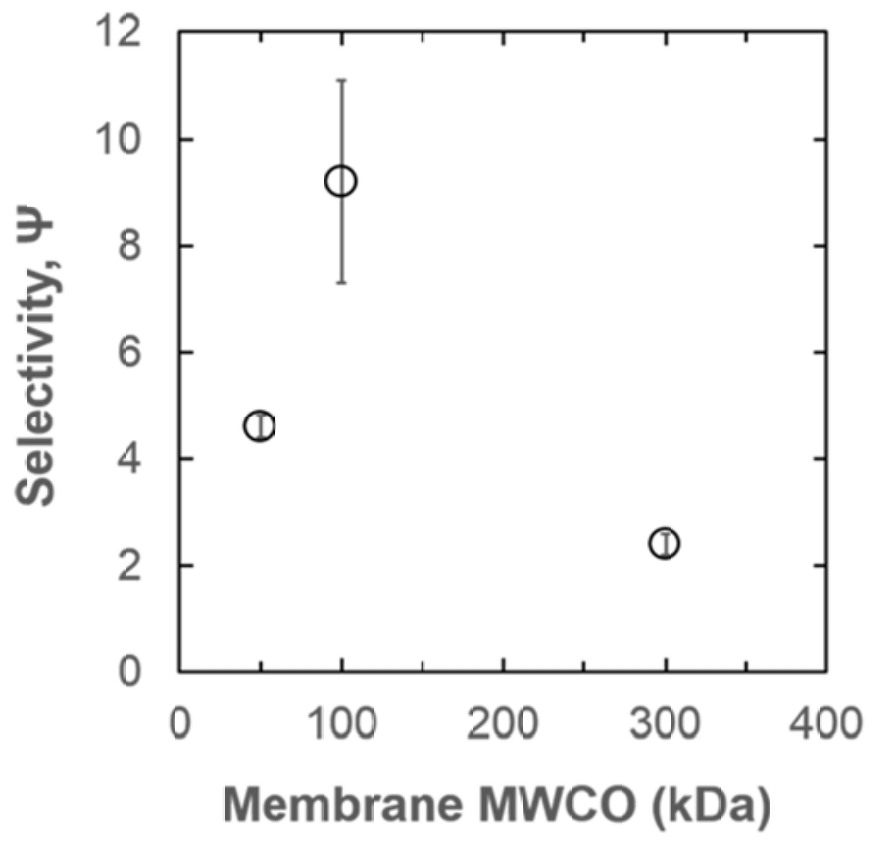

Fig. 3. Selectivity between the 3.0 and $16.8 \mathrm{kbp}$ supercoiled plasmids as a function of membrane MWCO. Only the optimal $\Psi$ values were plotted. Ultrafiltration experiments were conducted in TE buffer containing $300 \mathrm{mM} \mathrm{NaCl}$. The optimal $\Psi$ values were obtained at filtrate flux of 110,70 , and $5.2 \mu \mathrm{m} / \mathrm{s}$ for the 50,100 , and $300 \mathrm{kDa}$ membranes, respectively.

To confirm that the size-dependent transmission of the supercoiled plasmids was not unique to the Biomax ${ }^{\circledR}$ membrane, additional sieving experiments were performed using the Ultrace $^{\circledR} 100 \mathrm{kDa}$ regenerated cellulose membrane. As seen in Figure 4, the behavior of the 
Ultrace $l^{\circledR} 100 \mathrm{kDa}$ membrane is similar to that seen with the Biomax ${ }^{\circledR} 100 \mathrm{kDa}$ membrane, with much larger transmission of the $3.0 \mathrm{kbp}$ supercoiled plasmid compared to that of the 9.8 and 16.8 kbp plasmids. The maximum selectivity between the 3.0 and $16.8 \mathrm{kbp}$ plasmids was $\psi \approx 30$ at a filtrate flux around $40 \mu \mathrm{m} / \mathrm{s}\left(\mathrm{L} / \mathrm{m}^{2} / \mathrm{h}\right)$. The Ultracel ${ }^{\circledR}$ membrane also showed a large selectivity between the 3.0 and $9.8 \mathrm{kbp}$ plasmids, with $\psi \approx 12$ under these conditions.

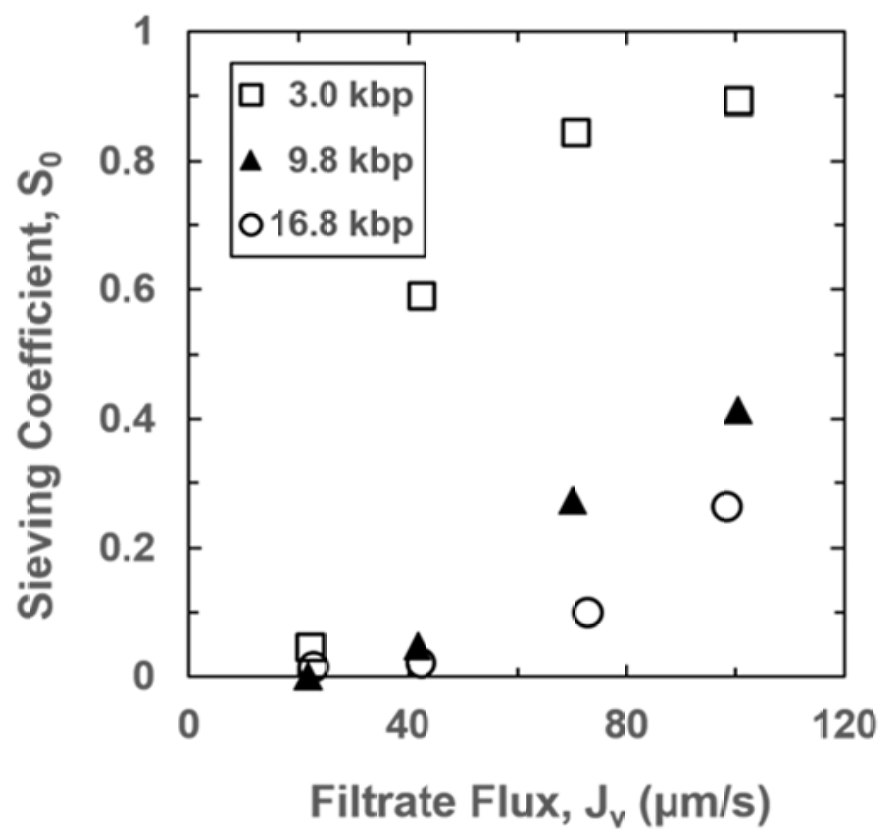

Fig. 4. Observed sieving coefficients of the 3.0, 9.8, and $16.8 \mathrm{kbp}$ supercoiled plasmids through the $100 \mathrm{kDa}$ Ultracel ${ }^{\circledR}$ membrane in TE buffer with $500 \mathrm{mM} \mathrm{NaCl}$.

Actual separation of the 3.0 and $16.8 \mathrm{kbp}$ plasmids was done by performing an ultrafiltration experiment with a binary mixture of the two supercoiled plasmids, each at a concentration of $0.25 \mu \mathrm{g} / \mathrm{mL}$ using the same solution conditions as in Figure 4. Data were obtained at a filtrate flux of $70 \mu \mathrm{m} / \mathrm{s}$ using an Ultracel ${ }^{\circledR} 100 \mathrm{kDa}$ membrane; this corresponds to a selectivity about 8.4 based on the data in Figure 4 . This higher flux was chosen to increase the transmission of the $3.0 \mathrm{kbp}$ plasmid and enhance the accuracy of the AGE used to evaluate the performance of the ultrafiltration process. Figure 5 shows the AGE image for filtrate and feed 
samples obtained 2 min after the start of the ultrafiltration. The first lane shows a $1.0 \mathrm{kbp}$ DNA ladder; Lanes 4 and 5 are the purified 3.0 and $16.8 \mathrm{kbp}$ supercoiled plasmids for reference. The $16.8 \mathrm{kbp}$ supercoiled plasmid sample contains some higher molecular weight species (faint band near the top of the gel in Lane 5), which could be plasmid dimers or low levels of the open circular isoform of this plasmid. The feed sample for the ultrafiltration experiment (Lane 3) consists of equal amounts of the 3.0 and $16.8 \mathrm{kbp}$ plasmids, with the lower band corresponding to the smaller $3.0 \mathrm{kbp}$ plasmid since it migrates faster through the gel during the electrophoresis; again, some high molecular weight species is seen near the top of the gel. The filtrate sample (Lane 2) shows only a single band corresponding to the $3.0 \mathrm{kbp}$ plasmid with no detectable levels of the $16.8 \mathrm{kbp}$ plasmid or the higher molecular weight species, consistent with the sieving coefficient data for the individual plasmids shown previously in Figure 4. These data clearly demonstrate that ultrafiltration can be used for the separation of different supercoiled plasmids on the basis of size.

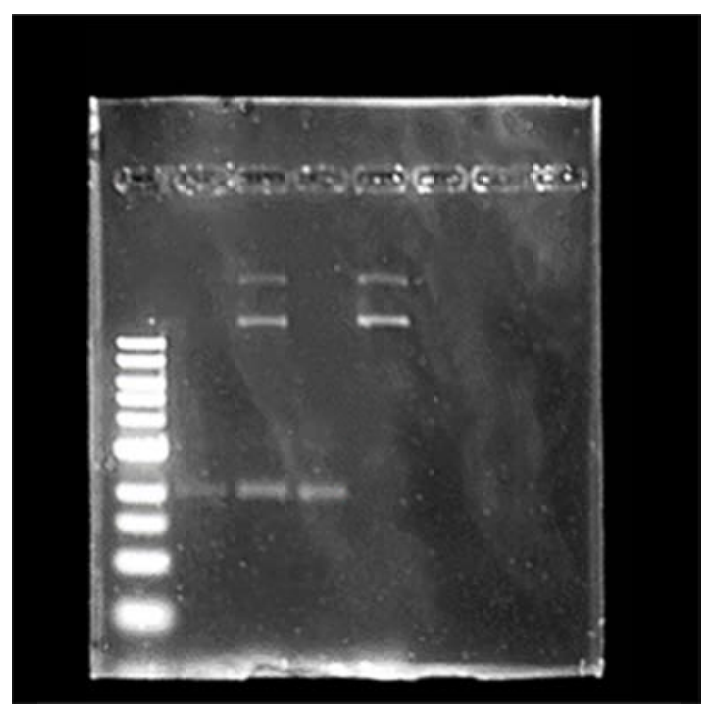

Fig. 5. Agarose gel electrophoresis (AGE) showing the separation of a binary mixture of the 3.0 and $16.8 \mathrm{kbp}$ supercoiled plasmids using an Ultracel $^{\mathrm{TM}} 100 \mathrm{kDa}$ membrane in TE buffer containing $500 \mathrm{mM} \mathrm{NaCl}$. Lane 1: linear $1 \mathrm{kbp}$ DNA ladder. Lane 2: filtrate sample collected at a filtrate flux of $70 \mu \mathrm{m} / \mathrm{s}$. Lane 3: feed sample. Lane 4: 
purified $3.0 \mathrm{kbp}$ supercoiled plasmid. Lane 5: purified $16.8 \mathrm{kbp}$ supercoiled plasmid.

\subsection{Linear plasmids}

A corresponding series of experiments was performed with linear versions of the three plasmids, each generated by enzymatic digestion of the corresponding supercoiled isoform. The linear isoforms have greater radii of gyration that the supercoiled isoforms. For example, the radius of gyration of the $3.0 \mathrm{kbp}$ linear plasmid is approximately $120 \mathrm{~nm}$, which is similar to that of the $9.8 \mathrm{kbp}$ supercoiled plasmid [19]. Figure 6 presents results for the linear 3.0 and $16.8 \mathrm{kbp}$ plasmids through the Ultracel $^{\circledR} 100 \mathrm{kDa}$ (left panel) and Biomax ${ }^{\circledR} 100 \mathrm{kDa}$ (right panel) membranes in TE buffer containing $150 \mathrm{mM}$ and $10 \mathrm{mM} \mathrm{NaCl}$, respectively. Similar results were obtained at other solution ionic strength and with both the smaller and larger molecular weight cutoff membranes. The sieving coefficients of the linear plasmid are considerably larger than the values seen with the supercoiled plasmids (Figures 1 and 4) at the same filtrate flux due to the greater elongational flexibility of the linear isoform; this is discussed in detail by Latulippe and Zydney [18] and has been exploited for the separation of the different DNA isoforms by ultrafiltration. The sieving coefficients for the two plasmids are very similar for all values of the filtrate flux, with differences of less than $8 \%$ (except for a single data point at $40 \mu \mathrm{m} / \mathrm{s}$ for the Biomax $^{\circledR} 100 \mathrm{kDa}$ membrane). Thus, the good selectivity for the supercoiled plasmids seen in Figures 1 to 5 is completely absent with the linear isoforms; the selectivity between the 3.0 and $16.8 \mathrm{kbp}$ linear isoforms was less than 1.2 under all experimental conditions. 

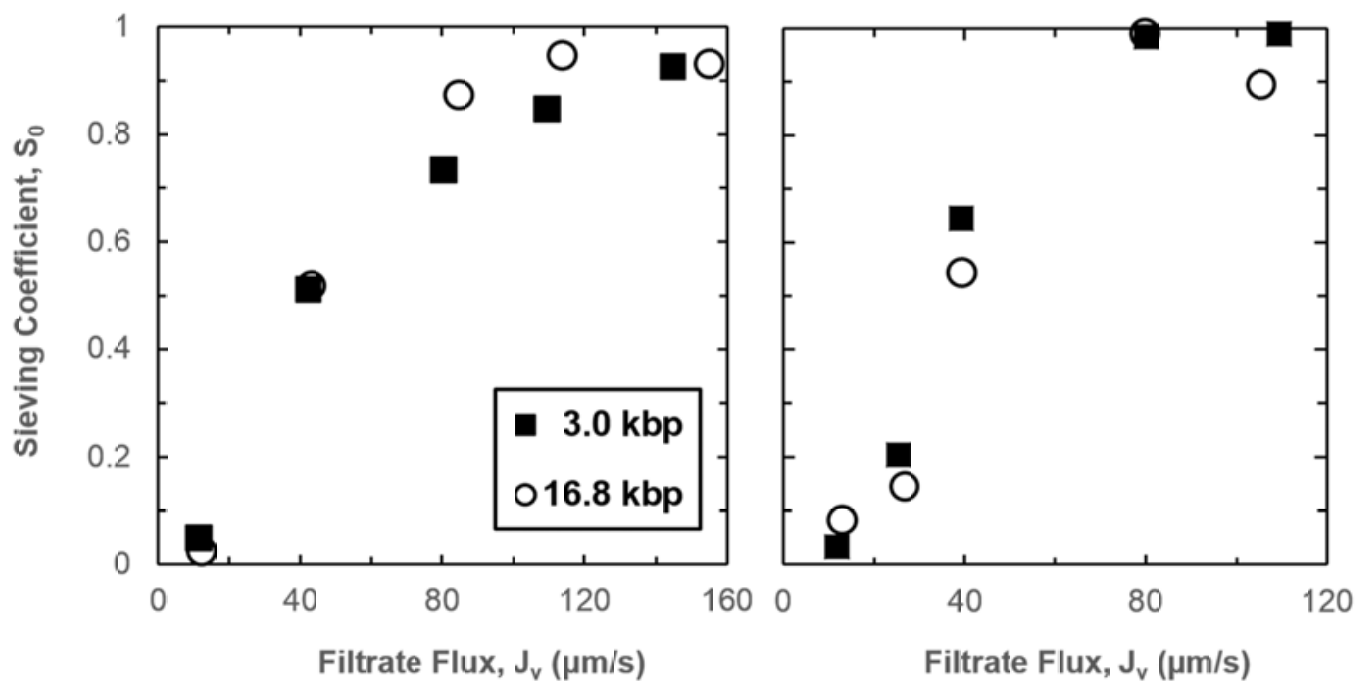

Fig. 6. Observed sieving coefficients of the 3.0, 9.8, and $16.8 \mathrm{kbp}$ linear plasmids through (a) the Ultracel ${ }^{\circledR} 100 \mathrm{kDa}$ membrane in TE buffer with $150 \mathrm{mM} \mathrm{NaCl}$ and (b) the Biomax $^{\circledR} 100 \mathrm{kDa}$ membrane in TE buffer with $10 \mathrm{mM} \mathrm{NaCl}$.

\subsection{Physical interpretation}

A number of previous experimental and theoretical studies have examined the transmission of linear polymers through narrow pores. Daoudi and Brochard [16] used scaling arguments to show that the critical volumetric flow rate required for passage of the chain through a pore scales as:

$$
q_{c} \approx \frac{k T}{\eta}
$$

independent of the polymer chain length (where $\mathrm{k}$ is the Boltzman constant, $\mathrm{T}$ is the absolute temperature, and $\eta$ is the solution viscosity). Sakaue et al. [21] used a force balance analysis to show that the passage of a linear polymer through a small pore is controlled by the injection of the first polymer "blob", which is again independent of the polymer chain length. Both molecular 
dynamic simulations [22] and experimental studies [23] have confirmed the universal transmission behavior of linear polymers with different chain length.

These results strongly suggest that the size-dependent transmission seen in Figures 1 to 5 is due to the unique molecular structure of the supercoiled plasmid isoform. Supercoiled DNA adopts a plectonemic (interwound) conformation with numerous branch points due to the helical "twists" in the circular plasmid (leading to local contortions or "writhe"). This branching is driven by the increase in entropy associated with the expanded conformation, but is enthalpically unfavorable due to the additional bending energy required to form the branches [24]. Previous studies have shown that the extent of branching is proportional to the size of the supercoiled plasmid [24]. The degree of branching is often quantified by the number of superhelix "ends" [25]. For example, Hammerman et al. [26] showed that a $1.868 \mathrm{kbp}$ supercoiled DNA was essentially unbranched $(\mathrm{N}=2)$, whereas a $5.243 \mathrm{kbp}$ molecule adopted a conformation with $\mathrm{N} \approx$ 3. Fathizadeh et al. [27] used molecular dynamics simulations to model the structure of supercoiled plasmids with lengths between 1.2 and $6 \mathrm{kbp}$ and showed that the average number of superhelix ends increased from 2 (no branching) for the smallest plasmid to $4.5 \pm 0.5$ for the 6 kbp plasmid. Boles et al. [28] used scanning electron microscopy to count the average number of branch points per DNA as 1.6 and 2.9 for a 3.5 and $7 \mathrm{kbp}$ supercoiled plasmid, respectively. Vologodskii and Cozzarelli [29] evaluated the branching frequency of supercoiled DNA as a function of DNA length using Monte Carlo simulations, with the results showing $\mathrm{N}=2,7$, and 12 for plasmids with lengths of 3,10 and $17 \mathrm{kbp}$ (similar to the size of the plasmids examined in this work). 
$\mathrm{Wu}$ and $\mathrm{Li}$ [30] developed a simple model for the transport of polymer chains with different topologies (e.g., branching) through small cylindrical pores. The critical flow rate was found to be:

$$
\frac{q_{c}}{q_{c, \text { linear }}}=\left(\frac{D}{\xi}\right)^{2}
$$

where $D$ and $\xi$ refer to the diameter of the pore and the "blob", respectively. Equation (3) was developed assuming that the minimum flow rate for chain passage is achieved when there is a balance between the confinement and hydrodynamic forces on the first "blob" of the polymer that enters the pore. In the limit of small pore size (i.e., membrane pore diameter $<<$ polymer length), the critical flow rate for injection of a branched polymer into a small pore was found to scale as

$$
\frac{q_{c, \text { branch }}}{q_{c, \text { linear }}}=n_{\text {branch }}^{1 / 4}
$$

where $n_{\text {branch }}$ is defined as the number of branching points of the hyperbranched chain (equal to the number of ends minus one). Thus, Equation (4) predicts that the critical flow rate increases by a factor of 1.6 in going from the 3.0 to $9.8 \mathrm{kbp}$ plasmids, with a 1.8 -fold increase in the critical flow rate for the $16.8 \mathrm{kbp}$ plasmid.

The experimental data for plasmid transmission as a function of filtrate flux can be used to estimate the critical flow rate by defining $q_{c}$ as the flux at which $S_{o} \approx 0.1$. The data in Figure 1 give values of the critical flux for the 3.0, 9.8, and $16.8 \mathrm{kbp}$ plasmids of 47,52 , and $81 \mu \mathrm{m} / \mathrm{s}$ based on linear interpolation of the sieving coefficients. Thus, the ratio of the critical flow rate for the $16.8 \mathrm{kbp}$ plasmid to that for the $3.0 \mathrm{kbp}$ plasmid is 1.7 , in excellent agreement with the factor of 1.8 given by Equation (4). Similar results were seen with the other membranes and with the $9.8 \mathrm{kbp}$ plasmid, providing further evidence that the observed differences in transmission of 
the different size supercoiled plasmids is due to differences in the underlying topologies associated with the writhe / branching of the longer plasmids.

Although there have been no prior experimental studies showing the effects of DNA branching on plasmid ultrafiltration, $\mathrm{Ge}$ and $\mathrm{Wu}$ [29] examined the transmission of linear and star-shaped polystyrene through ultrafiltration membranes with well-defined $20 \mathrm{~nm}$ pores. The polystyrene chains were synthesized by coupling "living" polystyl chains of different lengths using divinylbenzene. The linear polystyrenes showed much greater transmission than the corresponding star-shaped polymers (with the same total chain length), consistent with the behavior predicted by Equation (4) and in good qualitative agreement with the data obtained in this study for the ultrafiltration of supercoiled versus linear plasmids.

\section{Conclusions}

The results presented in this study clearly demonstrate the potential of using ultrafiltration membranes to separate supercoiled plasmids based on differences in their size (i.e., number of base pairs). Plasmid transmission through small pore ultrafiltration membranes is due to the elongation of the DNA chain in the converging flow field approaching the membrane pores, with minimal transmission below a critical value of the filtrate flux. However, the different size supercoiled plasmids have different critical flux, leading to greater transmission of the smaller plasmids. The Ultracel ${ }^{\circledR} 100 \mathrm{kDa}$ membrane showed a selectivity between the 3.0 and $16.8 \mathrm{kbp}$ plasmids as high as 30 , with similar behavior seen with the Biomax ${ }^{\circledR}$ polyethersulfone membrane. Note that a selectivity of 30 could provide a 100 -fold purification with $90 \%$ yield using a diafiltration process [18]. The potential for using ultrafiltration for separation of different size supercoiled plasmids was confirmed by agarose gels of filtrate samples obtained in an 
experiment using a binary mixture of the 3.0 and $16.8 \mathrm{kbp}$ plasmids. To our knowledge, this is the first quantitative demonstration of a size-based separation of large plasmid DNA using membrane ultrafiltration.

The reduction in transmission of the supercoiled plasmids with increasing chain length is a direct result of the morphology of the supercoiled isoform; no significant affect of plasmid size was seen during ultrafiltration of linear versions of the same plasmids. The supercoiled isoforms adopt a branched structure due to the under-twisting of the DNA, with the number of branches increasing with increasing chain length. The experimental results obtained in this study are consistent with the critical flux determined by scaling analysis for branched polymers, providing further confirmation of the origin of this size-based ultrafiltration behavior. Note that previous studies of plasmid ultrafiltration by Latulippe and Zydney [15] and Arkhangelsky et al. [31] did not observe any significant dependence of plasmid transmission on the size of the supercoiled DNA, although these experiments were done with considerably larger pore size membranes (1000 $\mathrm{kDa}$ molecular weight cutoff and $20 \mathrm{~nm}$ pores, respectively) which would be expected to have minimal selectivity based on the results in Figure 3.

Membrane systems could provide an attractive alternative for the purification of supercoiled plasmid DNA, both for laboratory analysis and in the preparation of gene therapy agents or DNA-based vaccines. Membranes are relatively inexpensive, and they provide much faster separations with greater throughput and scalability than size exclusion chromatography (SEC). Note that ultrafiltration would not be appropriate for separation of very small plasmids since plasmids less than about $3 \mathrm{kbp}$ do not adopt a branched configuration. Additional experimental studies will be needed to quantify the selectivity (or resolution) as a function of the size (and degree of branching) of the supercoiled plasmids. However, the data obtained in this 
study suggest that properly designed ultrafiltration processes could potentially provide higher resolution and lower cost separations of supercoiled plasmids than is possible using currently available SEC resins, particularly for very large size plasmids with highly branched structures.

\section{Acknowledgments}

The authors would like to acknowledge financial support from NSF CBET Grant 1505592. 


\section{References}

[1] G.N. Ferreira, G.A. Monteiro, D.M. Prazeres, J.M.S. Cabral, Downstream processing of plasmid DNA for gene therapy and DNA vaccine applications, Trends Biotechnol. 18 (2000) 380-388.

[2] K.J. Prather, S. Sagar, J. Murphy, M. Chartrain, Industrial scale production of plasmid DNA for vaccine and gene therapy: Plasmid design, production, and purification, Enzyme Microb. Technol. 33 (2003) 865-883.

[3] J. Meyers, D. Sanchez, Simple agarose gel electrophoretic method for the identification and characterization of plasmid deoxyribonucleic acid., J. Bacteriol. 127 (1976) 15291537.

[4] J.-L. Viovy, Electrophoresis of DNA and other polyelectrolytes: Physical mechanisms, Rev. Mod. Phys. 72 (2000) 813-872.

[5] D.B. Clewell, D.R. Helinski, Supercoiled circular DNA-protein complex in Escherichia Coli - Purification and induced conversion to an open circular DNA form, Proc. Natl. Acad. Sci. USA, 62 (1969) 1159-1166.

[6] M.M. Diogo, J.A. Queiroz, D.M.F. Prazeres, Chromatography of plasmid DNA, J. Chromatogr. A. 1069 (2005) 3-22.

[7] A. Rathore, A. Velayudhan, Scale-up and optimization in preparative chromatography: principles and biopharmaceutical applications, CRC Press, 2002.

[8] D.M.F. Prazeres, G.N.M. Ferreira, G.A. Monteiro, C.L. Cooney, J.M.S. Cabral, Largescale production of pharmaceutical-grade plasmid DNA for gene therapy: Problems and bottlenecks, Trends Biotechnol. 17 (1999) 169-174.

[9] J.K. McClung, R.A. Gonzales, Purification of plasmid DNA by fast protein liquid 
chromatography on superose 6 preparative grade, Anal. Biochem. 177 (1989) 378-382.

[10] G.J. Raymond, P.K. Bryant, A. Nelson, J.D. Johnson, Large-scale isolation of covalently closed circular DNA using gel filtration chromatography, Anal. Biochem. 177 (1989) $378-382$.

[11] R.T. Kurnik, A.W. Yu, G.S. Blank, A.R. Burton, D. Smith, A.M. Athalye, R. van Reis, Buffer exchange using size exclusion chromatography, countercurrent dialysis, and tangential flow filtration: Models, development, and industrial application, Biotechnol. Bioeng. 45 (1995) 149-157.

[12] R. van Reis, A.L. Zydney, Bioprocess membrane technology, J. Memb. Sci. 297 (2007) $16-50$.

[13] R. van Reis, S. Gadam, L.N. Frautschy, S. Orlando, E.M. Goodrich, S. Saksena, R. Kuriyel, C.M. Simpson, S. Pearl, A.L. Zydney, High performance tangential flow filtration, Biotechnol. Bioeng. 56 (1997) 71-82.

[14] D.R. Latulippe, K. Ager, A.L. Zydney, Flux-dependent transmission of supercoiled plasmid DNA through ultrafiltration membranes, J. Memb. Sci. 294 (2007) 169-177.

[15] D.R. Latulippe, A.L. Zydney, Elongational flow model for transmission of supercoiled plasmid DNA during membrane ultrafiltration, J. Memb. Sci. 329 (2009) 201-208.

[16] S. Daoudi and F. Brochard, Flows of flexible polymer solutions in pores, Macromolecules. 11 (1978).

[17] V.L. Singer, L.J. Jones, S.T. Yue, R.P. Haugland., Characterization of PicoGreen reagent and development of a fluorescence-based solution assay for double-stranded DNA quantitation, Anal. Biochem. 249 (1997) 228-238.

[18] D.R. Latulippe, A.L. Zydney, Separation of plasmid DNA isoforms by highly converging 
flow through small membrane pores, J. Colloid Interface Sci. 357 (2011) 548-553.

[19] D.R. Latulippe, A.L. Zydney, Radius of gyration of plasmid DNA isoforms from static light scattering, Biotechnol. Bioeng. 107 (2010) 134-142.

[20] R. Van Reis, S. Saksena, Optimization diagram for membrane separations, J. Memb. Sci. 129 (1997) 19-29.

[21] T. Sakaue, E. Raphaël, P.-G. De Gennes, F. Brochard-Wyart, Flow-injection of branched polymers inside nanopores, Europhys. Lett. 72 (2005) 83-88.

[22] M. Ding, X. Duan, Y. Lu, T. Shi, Flow-induced ring polymer translocation through nanopores, Macromolecules 48 (2015) 6002-6007.

[23] K.F. Freed, C. Wu, Comparison of calculated and measured critical flow Rates for dragging linear polymer chains through a small cylindrical tube, Macromolecules. 44 (2011) 9863-9866.

[24] A.V. Vologodskii, S.D. Levene, K.V. Klenin, M. Frank-kamenetskii, N.R. Cozzarelli, Conformational and thermodynamic properties of supercoiled DNA, J. Mol. Biol. 227 (1992) 1224-1243.

[25] J.F. Marko, E.D. Siggia, Statistical mechanics of supercoiled DNA, Phys. Rev. E 52 (1995) $2912-2938$.

[26] M. Hammermann, C. Steinmaier, H. Merlitz, U. Kapp, W. Waldeck, G. Chirico, J. Langowski, Salt effects on the structure and internal dynamics of superhelical DNAs studied by light scattering and Brownian dynamics, Biophys. J. 73 (1997) 2674-2687.

[27] A. Fathizadeh, H. Schiessel, M.R Ejtehadi, Molecular dynamics simulation of supercoiled DNA rings, Macromolecules 48 (2015) 164-172.

[28] T.C. Boles, J.H. White, N.R. Cozzarelli, Structure of plectonemically supercoiled DNA., J. 
Mol. Biol. 213 (1990) 931-51.

[29] A.V. Vologodskii, N.R. Cozzarelli, Conformational and thermodynamic properties of supercoiled DNA, Annu. Rev. Biophys. Biomol. Struct. 23 (1994) 609-643.

[30] C. Wu, L. Li, Unified description of transportation of polymer chains with different topologies through a small cylindrical pore, Polymer 54 (2013) 1463-1465.

[31] E. Arkhangelsky, Y. Sefi,, B. Hajaj, G. Rothenberg, V. Gitis, Kinetics and mechanism of plasmid DNA penetration through nanopores, J. Memb. Sci., 371 (2011), 45-51. 


\section{Nomenclature}

C

D

$\mathrm{J}_{\mathrm{V}}$

$k_{\mathrm{B}}$

$\mathrm{q}_{\mathrm{c}}$

$\mathrm{R}_{\mathrm{p}}$

$\mathrm{S}_{\mathrm{o}}$

$\mathrm{T}$

\section{Greek symbols}

$\Psi$

$\eta$

$\xi$
Plasmid concentration $\left(\mathrm{kg} / \mathrm{m}^{3}\right)$

Membrane pore diameter (m)

Filtrate flux through membrane $(\mathrm{m} / \mathrm{s})$

Boltzmann constant $(\mathrm{J} / \mathrm{K})$

Critical filtrate flow $\left(\mathrm{m}^{3} / \mathrm{s}\right)$

Membrane pore radius (m)

Observed sieving coefficient

Absolute temperature (K)

Membrane selectivity

Fluid viscosity (Pa s)

Diameter of a polymer "blob" (m) 


\section{Figure Captions}

Fig. 1. Observed sieving coefficients of the 3.0,9.8, and $16.8 \mathrm{kbp}$ supercoiled plasmids through the $100 \mathrm{kDa}$ Biomax $^{\circledR}$ membrane in TE buffer with $300 \mathrm{mM} \mathrm{NaCl}$.

Fig. 2. Selectivity between the 3.0 and $16.8 \mathrm{kbp}$ supercoiled plasmids as a function of filtrate flux. Ultrafiltration experiments were performed using $100 \mathrm{kDa}$ Biomax ${ }^{\circledR}$ membranes in TE buffer containing $300 \mathrm{mM} \mathrm{NaCl}$. Error bars were determined by standard propagation of error analysis.

Fig. 3. Selectivity between the 3.0 and $16.8 \mathrm{kbp}$ supercoiled plasmids as a function of membrane MWCO. Only the optimal $\Psi$ values were plotted. Ultrafiltration experiments were conducted in TE buffer containing $300 \mathrm{mM} \mathrm{NaCl}$. The optimal $\Psi$ values were obtained at filtrate flux of 110,70 , and $5.2 \mu \mathrm{m} / \mathrm{s}$ for the 50,100 , and $300 \mathrm{kDa}$ membranes, respectively.

Fig. 4. Observed sieving coefficients of the 3.0, 9.8, and $16.8 \mathrm{kbp}$ supercoiled plasmids through the $100 \mathrm{kDa}$ Ultracel ${ }^{\circledR}$ membrane in TE buffer with $500 \mathrm{mM} \mathrm{NaCl}$.

Fig. 5. Agarose gel electrophoresis (AGE) showing the separation of a binary mixture of the 3.0 and $16.8 \mathrm{kbp}$ supercoiled plasmids using an Ultracel $^{\circledR} 100 \mathrm{kDa}$ membrane in TE buffer containing $500 \mathrm{mM} \mathrm{NaCl}$. Lane 1: linear $1 \mathrm{kbp}$ DNA ladder. Lane 2: filtrate sample collected at a filtrate flux of $70 \mu \mathrm{m} / \mathrm{s}$. Lane 3: feed sample. Lane 4: purified $3.0 \mathrm{kbp}$ supercoiled plasmid. Lane 5: purified $16.8 \mathrm{kbp}$ supercoiled plasmid.

Fig. 6. Observed sieving coefficients of the 3.0, 9.8, and $16.8 \mathrm{kbp}$ linear plasmids through (a) the Ultracel $^{\circledR} 100 \mathrm{kDa}$ membrane in TE buffer with $150 \mathrm{mM} \mathrm{NaCl}$ and (b) the Biomax ${ }^{\circledR} 100$ kDa membrane in TE buffer with $10 \mathrm{mM} \mathrm{NaCl}$. 